\title{
A Journey Through Innovations: Remembering Hardships and Compassion
}

\author{
Jackson Radandt ${ }^{1}$ (D)
}

Received: 13 February 2018 / Accepted: 2 March 2018 / Published online: 29 March 2018

○) Springer Science+Business Media, LLC, part of Springer Nature 2018

By age three I had undergone three open heart surgeries at Children's Hospital of Wisconsin for hypoplastic left heart syndrome. Despite this, my childhood was fairly "normal" until I was 11 years old, the age I was diagnosed with endstage heart failure. This new development changed my "normal" life to one burdened by crises. It was then that I learned that only 20 years ago, most children with similar diagnosis died before their first birthday. I had been the beneficiary of innovations in surgery, intensive care and home care including being one of the first children enrolled in the interstage home-monitoring program. My journey through innovation did not end there. Because of heart failure, my only chance of survival was awaiting heart transplant with the support of a ventricular assist device (VAD). I became the youngest patient with a Fontan circuit to receive a Heartware VAD in the United States. This was my bridge to transplant which occurred 5 months later. Since then I have had the privilege of speaking about my experiences with innovative procedures in congenital heart disease (CHD) at various scientific and philanthropic forums. I realized only after being asked to write this editorial, that I had suppressed difficult emotional and physical burdens associated with my journey through innovation.

As I considered what to write for this editorial, I asked my family and Dr. Nancy Ghanayem, my medical mom and favorite cardiac intensivist, to help me recollect some of my more challenging experiences. They were not excited about rekindling those memories with me. What I did recall was the anger and frustration of being sick, being stuck in the hospital, the loss of freedom and being attached to monitors, intravenous lines (IV), and, sometimes, foley catheters. I no longer had privacy or time to be alone for more than an hour at a time. If I could get out of my room, it was to walk the

Jackson Radandt

jgradandt@gmail.com

1 Manitowoc, USA halls or see the fish in the downstairs aquarium. I should add, this monotony was not for days or weeks, but rather months.

My daily dread was the potential loss of the IV. I cannot begin to estimate the number of IVs I had throughout my life, not to mention failed IV attempts. The pain associated with an IV does not stop after insertion but rather remains painful and/or bothersome for during the entire time each one was in place. That along with getting my blood drawn from my other arm or my feet felt like torture. I normally had my blood drawn first thing in the morning... sometimes as early as four in the morning, a time that could and should be modified for long-term kids like me that should be asleep at this time. Thankfully, Dr. Ghanayem was there for me during these painful moments of IV insertion, amazingly even in the middle of the night. She did not place the IV, instead she would hold my hand and talk to me while someone else performed the procedure. Though these acts might seem minor, it is those acts of compassion by her, Dr. Michele Frommelt and other staff members that were important for my wellbeing and sanity.

Hospital life was long and difficult. One of the worst stretches was when I had dangerously low sodium levels in my body. I was put on fluid restriction which allowed for $2 \mathrm{~L}$ of water each day. Taking a diuretic and consuming salt packets did not help. When my sodium dropped early during this crisis I drifted into a stroke like state where I slurred my words and I had facial drooping. Luckily this was dealt with quickly and only became a serious problem twice. I really struggled swallowing the salt packets and often threw them up, until someone came up with the clever idea to use $3 \%$ solution as my carrier fluid so I did not have to take the terrible tasting pills. Again, little things like that made my days easier. I was so incredibly thirsty throughout this entire experience that I would beg the doctors for even a few extra sips of water. Fluid was always on my mind and I had a difficult time when not being able to drink whenever I pleased. I planned my day around rationing when I could 
drink. The water restriction was lifted after my life-saving HVAD surgery.

Physical exhaustion did take its toll. My sickness affected me in every imaginable way, including my mental state. I was tired of being sick, tired of the hospital, tired of food, tired of waiting for a heart transplant, and tired of everything in general. I had become depressed. My faith and knowing this was God's plan, along with my family, doctors, and nurses trying everything to keep me happier is what helped me through this. The support from family and the staff was a huge help in every way. My doctors and nurses would play board games and cards, they kept me involved in decisions and held rounds in my room so I could hear everything and ask questions. Having visitors and family staying with me 24/7 helped tremendously. Being able to see aunts and uncles again always brightened my day. Even though I was sad every time they had to leave I still enjoyed the time I got to spend with them.

After months in hospital I just wanted my transplant and I wanted to go home. This was the absolute worst part of being in the hospital. I could not see an end. I had no way of knowing when the perfect heart would come for me. I realized that it could take years and that was terrible for me. I was trapped in a tiny yellow hospital room and I thought nothing would help me. I thought I'd never get my heart and I thought I would never return home. This feeling continued well after the HVAD surgery. Even though I was getting physically better, my mental health was at an all-times low. I had overwhelming depression and, although it was difficult, I tried to stay positive. The staff compensated for my depression and did everything to help me. Post-HVAD implant they allowed me to be disconnected more than ever before, and I was constantly reassured that I was going home. My hopes rose again when I was told that I had the ability to go home with an HVAD and wait for my transplant there.

I was so happy to go home but very anxious about it too. After discharge, the hospital lifestyle did not end. We made many visits to the hospital and the HVAD required constant maintenance. I dreaded the daily, uncomfortable dressing changes and the constant INR checks. I had unbelievable anxiety while at home on the HVAD because I became mentally dependent on the protections offered by the hospital and constant monitoring. I always worried the HVAD would malfunction, no one would be around to hear the alarm and that something would happen to me. The anxiety was so intense that I phoned Dr. Ghanayem almost nightly to have her reassure me that I was safe and that I would receive a heart.

After nearly 7 months of waiting I finally got the call that there was a heart for me. I was in the hospital only 11 days after the surgery. I am forever grateful for my donor family for giving me a second chance at life. Nearly 5 years later, I now am a junior in high school, participate in junior leadership, have a driver's license and look forward to college (and medical school). I have had amazing opportunities to speak and advocate for advancements in the care of CHD to doctors, scientists, advocacy groups, and lobbyists. I have been admitted to the hospital three times since my transplant. I know I will face more challenges and that the hospital care may always be part of my life. I have had numerous cardiac catheterizations and other procedures and can communicate what works best for me to the anesthesiologists. I undergo constant surveillance of my immunosuppression drug levels that sometimes leads to lab draws twice a week.

As we continue the journey through innovation in helping children with congenital heart disease, I implore all involved not to lose sight of the emotional and physical burden imposed on patients and their families. Emotional and physical wellbeing for each patient depends on shared responsibility between doctors, physician assistants, nurses, therapists, other hospital staff, friends, and family. I was fortunate to have benefitted from innovative, yet also compassionate care. 